\title{
A New Risk-based Early-warning Method for Ship Collision Avoidance
}

\author{
Yingfan Chen ${ }^{1}$; Shuzhe Chen²; Pieter van Gelder ${ }^{3}$; Cheng Xie ${ }^{4}$ and Liwen Huang ${ }^{5}$ \\ Yingfan Chen; Doctoral student; School of Navigation, Wuhan University of Technology; No. 1178, Heping Avenue, Wuhan, Hubei, \\ China; E-mail: 307869092@qq.com. \\ Shuzhe Chen; *Corresponding author; associate professor; National Engineering Research Center for Water Transport Safety, School \\ of Navigation, Wuhan University of Technology; No. 1178, Heping Avenue, Wuhan, Hubei, China; E-mail: uuucyf@outlook.com. \\ Pieter van Gelder; Professor; TU Delft, Faculty of technology, policy and Management, Safety and Security Science Group; Room \\ C1.170, Jaffalaan 5, 2628 BX Delft, Netherlands; E-mail: p.h.a.j.m.vangelder@tudelft.nl. \\ Cheng Xie; Doctoral student; School of Navigation, Wuhan University of Technology; No. 1178, Heping Avenue, Wuhan, Hubei, China; \\ E-mail: 382788568@qq.com. \\ Liwen Huang, Professor; School of Navigation, Wuhan University of Technology; No. 1178, Heping Avenue, Wuhan, Hubei, China; \\ E-mail: uuucyf@163.com.
}

\begin{abstract}
In the case that ship operators may not be aware of the potential risks of environmental factors in situation of high causation probability during the initial stage of the geometric probability analysis process, it is likely that highergrade collision accident measures will not be taken. However, if any risks is told to the ship operators, more effective and intentional measures can be taken in time. Moreover, if the causation probability corresponding to environmental factors is no less than the risk early warning critical value calculated based on historical collision accident data, there would be a high-risk level that a collision may occur. A new method is put forward based on quantitative analysis of environmental factors and previous collision statistics to provide early warning of any accident risk, and a risk earlywarning critical value (REWCV) can be obtained based on this simple but highly operational and practical method. A case study of Three Gorges Reservoir in China indicates that the range of environmental factors where the probability of collision accident grows rapidly is consistent with environmental limits defined by Chinese maritime standards. In addition, the relationship between the risk early-warning critical value and the number of previous collision accident is also clarified.
\end{abstract}

Keywords: ship collision accident, early warning, probability of causation, environmental factor

\section{Introduction}

Risk is an uncertain event or condition that affects at least one objective if it occurs. As a specific type of risk, ship navigation-related risks involve potential circumstances which may cause possibility of great economic loss and serious human casualty, thus have always been a constant concern. A ship-ship approaching situation may result in a high risk of ship collision accident where the safety factors can be crucial in a general human-shipenvironment system. Based on analysis of collision avoidance factors and threshold indicators of International Regulations for Preventing Collisions at Sea (COLREGs), where regulations are primarily presented at the micro level of geometric probability, the following safety factors are selected:

(1) Visibility;

(2) Traffic density including the intensity of fishing boats or any other types of vessels;

(3) Ship maneuverability (especially stroke and turning under the circumstances);

(4) Night background light (such as shore light or backscatter light of the light of the ship); 
(5) Those situations such as wind, waves and currents or situations near any dangerous object; and

(6) The relationship between the draft and the available water depth.

Refer to Clause 6.1 of COLREGs, influencing factors are not generalized and only some specific practices and operating rules are given.

The probability of ship collision accident, denoted by $P$, can be divided into two independent parts, namely probability of causation $P_{C}$ and probability of geometric $P_{G}$ (Macduff, 1974). The former one, namely probability of causation $P_{C}$, refers to a macroscopic concept, which means the probability of accidents in a manner that accidents always occur but are not directly against any concrete ship, driver or pilot in a specific water area. $P_{C}$ might be determined by contribution of each environmental factor in a human-ship-environment system, and it is unrelated to geometry parameters (Hanninen, 2009). Alternatively, probability of geometric $P_{G}$ is more of a microscopic description for specific objectives such as ships, navigation marks, marine constructions etc. If the size, trajectory, speed and course of ships are defined, the probability of geometric pays more attention to the ships' scale and motion for calculating the total $P$, thus the microscopic factors are of more concern.

Generally, $P_{C}$ is assumed for a certain waterway and only a few studies took it in accident case analysis. It was proposed that $P_{C}$ can be applied to the entire water way after a local part value is determined based on the historical accident data (Kaneko, 2002). In contrast, the probability of geometric $P_{G}$ shows more of specific parameters which would be relevant only in particular accident cases. These parameters may include the area and traffic volume of water body or ship's size, speed and course etc. $P_{C}$ corresponds to management-level decision making and are suitable for large-scale analysis. On the other hand, $P_{G}$ is more of operation-level decision making and is accurate in a more small-scale level. According to the former literature (Montewka, 2010), probability of ship collision accidents can be expressed as:

$$
P=P_{C} \cdot P_{G}
$$

Depending on the scale of the sailing ship, the relation between $P_{C}$ or $P_{G}$ might be interactive. Typically, $P_{C}$ are initially assumed for a large scale area, but an accurate geometric model is necessary for collision accident of a ship-ship approaching situation (Goerlandt, 2011).

The probability of ship collision $P$ changes as the distance between two ships alters, leading to the fact that the environmental factors related to the human-ship-environment system should be considered. When ships are spaced in a large distance and various environmental factors might be involved, operators may not notice these potential environmental elements. The collision risk is mostly determined by operator' experience, and necessary measures may not be adopted. In this situation, the human factors are dominant. In a more risky situation when operators focus more on the dangerous environmental factors, more attention is concentrated and the accident is mainly caused by the disadvantageous surroundings, thus human factors should not be dominant.

Considering a ship-ship approaching situation, operator would be aware of the risk if the ships are getting closer. Human factors are dominated in determining the total probability $P$. Note the environmental factors can be also crucial in this case. For a large distance situation where the ships are spaced, even though environmental factors do not directly cause collisions, behaviors of operators may still be influenced (Hara, 1995). In addition, probability of geometric $P_{G}$ will take larger proportion of probability $P$ if ships are getting closer.

A navigating ship owns a constantly changing human-ship-environment system where environmental factors 
vary by different meteorological and hydrological conditions but regardless the effect of other ships. However, environmental factors do not change significantly when two ships start to approach and then the collision occurs. At the same time, those factors associated to the navigation environment do not typically change during any local navigation period when ships cross a relatively short route or navigable waters, so that they may be assumed as constants (Balmat, 2009).

$P_{C}$ exsits in different aspects (human, environmental, etc.) and they are changing. Historical accident-related data show that $P_{C}$ may be positively affected by human factors. Similarly, if operator actively responds to the effects of external environmental factors and moderate actions are taken as much as possible, the $P_{C}$ from environmental factors would fall. For example, in situation of severe environment such as poor visibility, strong wind or intensive currents, captain should be allowed to go to the bridge and constant VHF communications should be performed to understand the intentions of other ships. Otherwise if the operator is not sensitive to the environment or does not response to a harsh environment, or even neglect observation in a tired situation, $P_{C}$ might be negatively affected which leads to the rise of the value.

In a single ship collision accident, the occurrence of accident is among the interaction system of people-shipenvironment. In the existing maritime accident samples, there always exists certain navigational environment characteristics, and human \& ship mistakes may be caused by vastly different reasons. Considering several number of accident samples, some of which may occur due to too strongly oppressive environmental factors while the human operation is correct. In some other accidents, the relation between human and environmental factors might be out of balance where this fact is not only affected by the insufficiently oppressive environmental factors, but is also caused by operator's neglect of vigilance.

However, during conventional management procedures such as ship inspection, the probability of those maritime accidents due to failures of ship instruments would be small. Thus, effects of the inherent features, such as maneuverability, should be of more concerned for the ship factors. As a whole, the ship factors does not fundamentally change the trend of accident risks, but their function is to enlarge or reduce the magnitude of the accident risk. In case where only the accident risk is studied, the following expression should be satisfied:

$$
P=P_{s} \otimes\left(P_{h} \oplus P_{e}\right)
$$

where $P$ is the accident risk, symbol $\bigoplus$ shows the interaction between the risk of human factor $P_{h}$ and the risk of environmental factor $P_{e}$, and symbol $\otimes$ denotes that this relation can be amplified or reduced by risk of ship factor $P_{S}$. Based on analysis of the historical accident, the risk of human factor $P_{h}$ may be within the zone $[-1,1]$, reflecting the integrated effects of human factors in collision accidents may be attenuated or even eliminated. Moreover, if a large number of accident samples are involved, $P_{h}$ may approach a stable value or yield a certain distribution (similar to a normal distribution or other modes).The objectiveness of environmental factors leads to the general assumption that their risk $P_{e}$ are within the zone $[-1,1]$, and statistical analysis of multiple accident samples may ensure that they would approach a zone or threshold, which is also the focus of this study. In addition, the risk of ship factor $P_{S}$ is within the zone $(0,+\infty)$. They can be partitioned in $(0,1)$ and $(1,+\infty)$ components which respectively reflects amplification and reduction of the integrated human and environmental risk. 


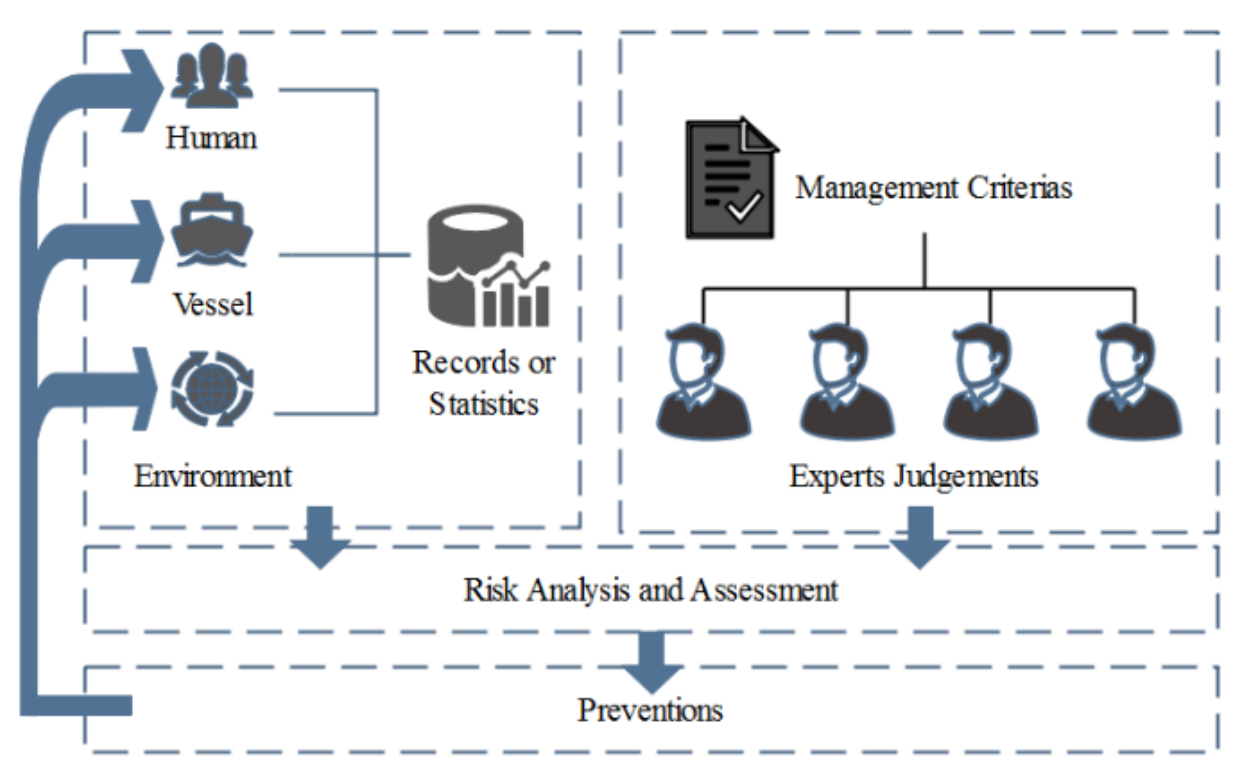

Fig. 1 Positive and negative effects of factors related to human-ship-environment interaction

If the safety management of maritime jurisdiction is regarded as a macroscopic goal and there exists a large number of accident samples, the corresponding risk is considered from a macro point of view that the ship characteristics may be described by a certain linear or nonlinear function where such characteristics vary with time and space, and remain a constant at small spatial and temporal scales. Moreover, human factors are not able to measure at present due to the fact that some of components, physiological or psychological, are difficult to quantify. On the whole, the human factors with positive and negative operations should be counterbalanced mutually, or tend to a certain stable value, or conform to a certain distribution when large samples are available.

In case of a large number of collision accidents, effects of ship and human factors would act in a certain proportion or conform to a certain distribution (Darbra, 2004).The probability of causation $P_{C}$ of both ship factor and human factor may even be compensated (Fig. 1). Irrespective the variation and interaction of both ship and human factor, and assume that the statistic knowledge of environmental factor is obtained from historical collision accidents, the accident risk $P$ may be dangerous and can be regarded as risk indicator if the risk of environmental factor $P_{e}$ reaches a historical high level. Thus, an early-warning system might be developed for an emergency situation if causal probability of environmental factors are quantified based on previous accidents data. In other words, if the risk early-warning critical value (REWCV) of environmental factors can be determined in advance, the total collision probability $P$ may be estimated and safety situation can be guaranteed (Chen, 2014).

\section{Quantification of $P_{c}$}

The number of collision accidents is definite within a statistical period of a specific water channel, but the width of channel may be wide (no less than $600 \mathrm{~m}$ ) or narrow (less than $100 \mathrm{~m}$ ) when an accident occurs. The statistics is firstly performed on the length of channels with various widths to master the effect of channel width on collision accidents. Subsequently, the ratio between the channel length (fixed width) and the total length of channels is extracted. Then the probability of effects of channel widths on collision accidents may be determined.

One proposed a method in which environmental factors can be quantified based on historical collision accidents data (Papanikolou, 2014). The method begins with assuming a certain number of collision accidents in a period and also the accident numbers due to some of the environmental factors, thus the effect of each factor can 
be quantified to determine every probability of causation. Then, the total environmental value can be calculated as the sum of each individual probability. Note the proportion for each probability component might vary in magnitude, this is related to both hypothetic and historical accident data. For example, visibility is regarded as a vital navigation factor which ranges from less than $50 \mathrm{~m}$ to more than $1000 \mathrm{~m}$. Normally in a good visibility situation, visibility does not play a critical role in accident probability. However, visibility shows greater importance as visible distance is decreasing. Note the trend of this change is even nonlinear among these different discrete values. However, effects of visibility on the probability of accidents are nonlinear for different degrees of discretization.

The causal probability of a certain environmental factor $P_{e}$ is determined by three independent parts:

1). number of collision accidents $n$ under a certain environmental factor;

2). occurrence frequency $F_{Z}$ of a certain environmental factor;

3). statistic time interval $n_{0}$ for collision accidents

If the total number of collision accidents, as well as the level and rate of each environmental factor is derived, then $P_{e}$ can be expressed as:

$$
P_{e}=\frac{n}{F_{z} \cdot n_{0}}
$$

where two functions are related, including:

a. performing the statistics of the collision accidents in waterways with various widths in a period;

b. actually correcting the probability of effects in view of collision accident frequencies in channels in different widths based on statistics of channel length (various widths) in a specific waterway.

Afterwards, this algorithm is replaced by Bayesian Theory to solve the effects of each environmental factor on accident probability. The equations are as follows:

$$
P(B \mid A) \cdot P(A)=P(B) \cdot P(A \mid B)=P(A B)
$$

or

$$
P(A \mid B)=\frac{P(A) \cdot P(B \mid A)}{P(B)}
$$

where $P(A \mid B)$ represents the probability of collision accidents in the case of a certain factor (grade) $\mathrm{B}, P(B \mid A)$ represents the probability of collision accidents in case of a certain factor (grade) $\mathrm{A}, P(A)$ represents the probability of collision accidents within the statistical period, and $P(B)$ represents the probability of existence of a certain factor (grade) B, which may be replaced by its frequency within the statistical period.

The probability of causation due to the environmental factors $P_{i}$ presents the cumulative probability in a collision accident for all environmental factors. If environmental factors are independent, their sum is the factor occurrence of Pi which can be expressed as (Li, 2012):

$$
P_{i}=\sum_{i=1}^{k} P_{e, i}
$$

It is worthwhile to point out that the ship density and traffic volume are not independent, and it is generally difficult to describe their correspondence. It is assumed that they are independent in this study. Besides, $P_{i}$ ought to be less than unit and our calculated results also proved that, but there is indeed such possibility that $P_{i}$ might be greater than 1 . Rigorously speaking, $P_{i}$ utilized in Eq. (6) is only the total probability of causation for ship 
accidents due to navigation environmental factors. Because the number of ships in the actual water areas in the statistical period is not taken into account, its representation significance lies in the relative magnitude of environmental factors under different historical accidents.

\section{Early-warning method}

Once the number of accidents in a period are derived, the corresponding threshold of ship collision accidents due to multiple environmental factors can also be determined. During this period, each environmental factor and the corresponding probability of causation may also change continuously. When the probability of causation related to all environmental factors is no less than the calculated value based on historical accident data, the accident probability of navigation environment may be regarded as the warning value (Toffoli, 2003). It is generally believed that the length of the ship domain in inland waters is 2-5 times of the ship length along the motion direction (Xu, 2004). An early warning should be issued when the distance between two ships is five times of the ship length (Fan, 2013).

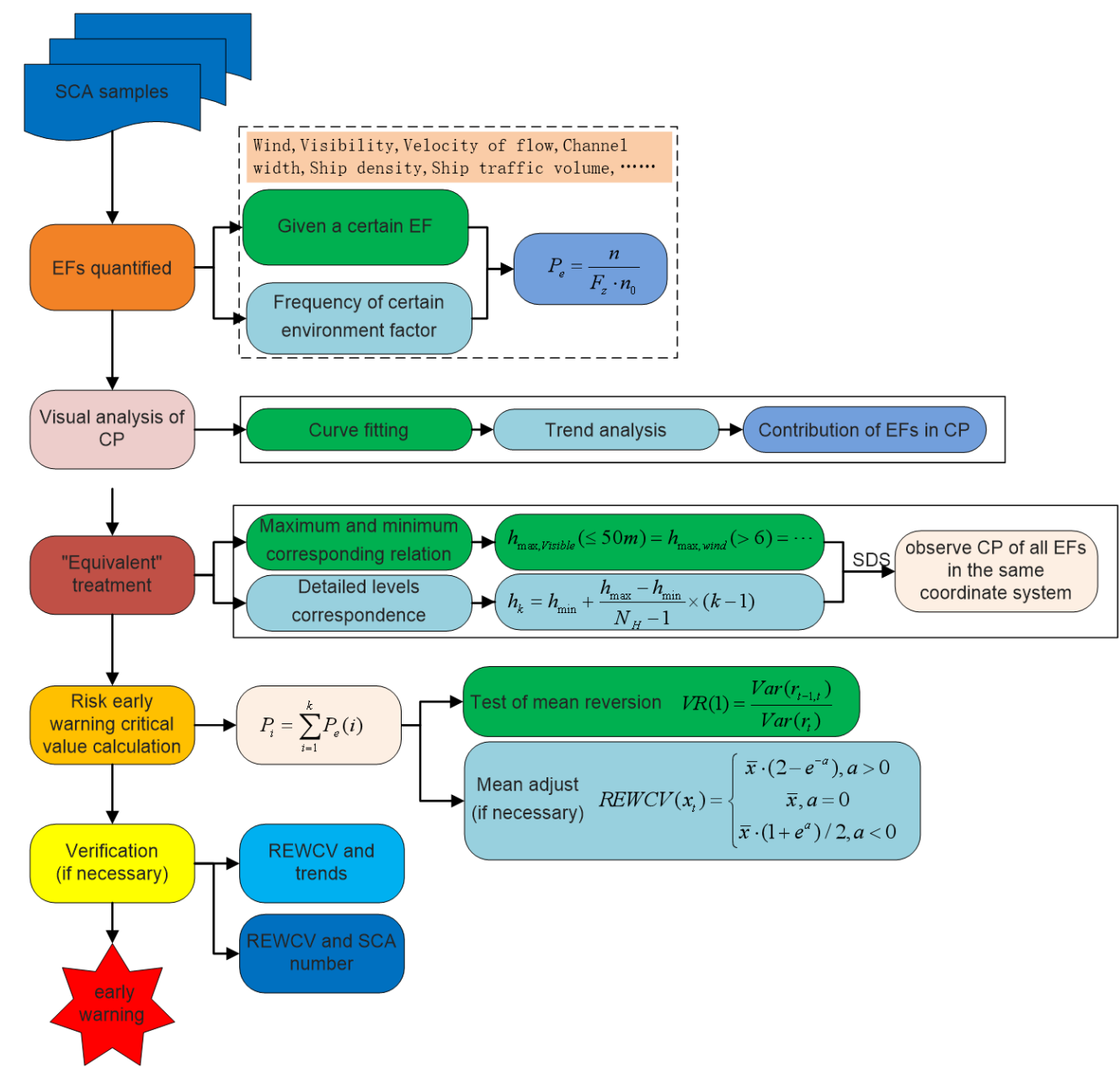

Fig. 2 Flow diagram of the early warning method

Irrespective of any human or ship factor, the environmental probability of causation would be up to a threshold value, suggesting the occurrence of an accident, so that ship operators should be vigilant for issuing a warning (Toffoli, 2005). This threshold value refers to the fact that the risk of accidents is mainly amplified or reduced by ship factors, but the overall positive and negative effects of human factors on the probability of accidents are weakened mutually, or tend to a stable value, or distributed based on the statistical analysis of a large number of historical accident samples. Thus, the key navigation environment factors are sufficient to measure 
the risk of accidents to a certain extent. The measuring method is by the threshold (critical value) analysis which is described later in this study. The probability of geometric would be evaluated subsequently and the early warning method is shown schematically in Fig. 2.

\subsection{Data sorting and quantification}

The number of accidents and the frequency of different environmental factors levels can be determined by collecting and sorting the previous investigative reports. Generally in a formal accident investigation report, the collision accidents are located, information regarding the water channel (including width, water depth and bending radius) should also be gathered. It is also important to know the corresponding meteorological and hydrological conditions (including wind velocity, range of water velocity and visibility). Density of the ships and traffic volume can be determined based on automatic identification system (AIS) tracker or any other navigation apparatus.

In some cases, it is not easy to directly obtain the environmental factors' frequencies rather than calculating them indirectly. The relatively wind velocity and visibility level frequencies in a waterway can be collected from the meteorological authority. The year-round daily flow rates and water levels are necessary to determine the frequency of a certain water velocity. On this basis, boundary conditions can be determined and the water velocity might be simulated. The frequencies of different water velocities in a waterway are subsequently acquired in a similar way based on the corresponding flow rates and water levels. Thus, the frequencies of different water velocities can be represented by the corresponding flow rates.

The length of a channel is firstly calculated when its width is fixed, then to calculate a certain width frequency by dividing the length of the entire water channel. Thus, the time (number of days) appears as a certain percentage of the whole day at a certain channel width when an accident occurs in a waterway. The water areas within a certain distance around previous collision accident sites should be taken into account to determine the frequency of a certain ship density around the ship. The number of ships per hour and their corresponding distribution are also calculated. Afterwards, the frequencies of different ship densities are calculated by dividing the density frequencies of all ships. The frequencies of different traffic volumes provided by the maritime administration authority may be utilized to monitor traffic volumes in different regions near the accident location, and the number of ships going through each region per hour is counted.Thus, the frequency of a certain traffic volume may be calculated by dividing the frequency of traffic volume in each level by the taotal traffic volume.

\subsection{Visual analysis of $P_{c}$}

When historical accident data are collected and the frequencies of different environmental factors are determined, the probability of causation corresponding to different environmental factor levels can be calculated by applying Eq. (2). By plotting the different levels of a given environmental factor along the X-axis, and the probability of causation of individual environmental factor levels along the $Y$-axis, discrete points shown in a graph can be fitted by numerical curve fitting method (2012). The trend of probability of causation can be derived, and the sharp changes of a curve's slope denote the dramatic increase or decrease of the probability of causation, showing a major role in determining the values.

\subsection{Equivalent treatment}

Different environmental factors correspond to various dimensions, which calls for a uniform standard to 
evaluate. To solve this problem, Subjective Danger Sensation (SDS) system was proposed (Statheros, 2008) to observe the $\mathrm{P}_{c}$ of all environmental factors in a same coordinate system.

In any SDS classification system, different "grades" are assigned to various environmental factors levels. However, it is difficult to define the relationship between the environmental factors and their levels. It is chiefly necessary to map the relations between the maximum quantitative data with an index $h_{\max }$, and also the minimum quantitative data with an index $h_{\min }$, so that the a quantitative data under a given index $h_{k}$ may be presented. The classification process of a grade $N_{H}$ is performed by:

$$
h_{k}=h_{\text {min }}+\frac{h_{\text {max }}-h_{\text {min }}}{N_{H}-1} \times(k-1), N_{H}>1, N_{H} \in N, k=1,2, \cdots, N_{H}
$$

where $h_{\max }$ and $h_{\min }$ respectively means the maximum and minimum of a given index, $h_{k}$ is the corresponding quantitative data, $N_{H}$ is the Index evaluation grade. Then, the quantitative evaluation criteria for each environmental factor level is expressed as:

$$
h_{k}=\left\{h_{1}, h_{2}, \cdots, h_{N_{H}}\right\}=\left\{h_{\text {min }}, h_{\min }+\frac{h_{\max }-h_{\min }}{N_{H}-1}, \cdots, h_{\max }\right\}
$$

The extreme values of these environmental factors, such as $h_{\max }$ and $h_{\min }$, are defined based on historical accident statistics. Moreover, a concept named maneuver danger degree is introduced in view of these factors in different dimensions to perform comparison and calculation in a same system. As described in many Chinese literatures (Suyi Li, 2012) where experts and ship operators are invited to carry out subjective evaluation; they think that the effects of environmental factors which is below (or above) a certain degree for the maneuver danger degree are almost the same. This is the basis for determination of the equivalence of the extreme value 0 or 1 in this paper. Based on this, various environmental factors are classified after their extreme values are set. It is believed that the various maneuver danger degrees can be placed into a one-to-one relationship, so that the correspondence danger between an environmental factor and another one may be determined. In the end, various factors of different dimensions are unified.

As an example, considering two environmental factors, namely visibility and water velocity, as two indexes in SDS system. The visibility of less than $50 \mathrm{~m}$, as well as the water velocity of greater than $2.5 \mathrm{~m} / \mathrm{s}$, are defined as the maximum threshold, thus the following equation is set as

$$
h_{\text {max,visibility }}(<50 m)=h_{\max , \text { water velocity }}(>2.5 \mathrm{~m} / \mathrm{s})=1
$$

where number "1" represents the highest SDS grade. In a similar way, the minimum values of these two environmental factors can be expressed as

$$
h_{\text {min,visibility }}(>1000 m)=h_{\text {min,water velocity }}(\leq 0.5 \mathrm{~m} / \mathrm{s})=0
$$

where number "0" represents the lowest SDS grade. Thus, the corresponding relationships for the different levels of both environmental factors can be determined by Eq. (7) and Eq. (8). Note the appropriate calculation methods must be adopted to precisely determine the relationships among different levels. Similarly, the corresponding $\mathrm{P}_{c}$ to all environmental factors can be observed in a same coordinate system.

\subsection{Calculation of risk-warning critical value}

After the $P_{c}$ values are derived, the probability of collision accidents can be determined by Eq. (2). If the samples are in a sufficient number, the $\mathrm{P}_{c}$ values should exhibit a reversion to the mean, leading to the fact that 
these values would fluctuate around the critical or warning value. Alternatively, this also means that the critical values of environmental factors are independent of human and ship factors. Thus, the mean reversion method might be used for not only verifying the $\mathrm{P}_{c}$ trends from the previous accidents, but also for eliminating effects of human and ship factors in collision accidents. Then, the risk-warning critical value of environmental factors can be known based on the early warning means, and the ratio variance method (Wright, 2000) can be used to verify whether these $\mathrm{P}_{c}$ values for different accidents are sorted chronologically. For the time series $\left\{x_{t}\right\}_{1}^{n}$, the variance ratio can be calculated by:

$$
\begin{gathered}
\operatorname{VR}(k)=\frac{\operatorname{Var}\left(r_{t-k, t}\right)}{k \cdot \operatorname{Var}\left(r_{t}\right)}, k \in(0, t), t \in\left(1, x_{t}(n)\right] \\
r_{t-k, t}=\log \left(\frac{x_{t-k}}{x_{t}}\right)
\end{gathered}
$$

where the variance ratio $V R(k)$ represents the proportional relationship between a large-scale variance of $\operatorname{Var}\left(r_{t-k, t}\right)$ and a small-scale variance $\operatorname{Var}\left(r_{t}\right), t$ is between 1 and the number of $x_{t}(n)$. Thus:

$$
\operatorname{VR}(1)=\frac{\operatorname{Var}\left(r_{t-1, t}\right)}{\operatorname{Var}\left(r_{t}\right)}
$$

If $V R(1)$ is less than 1 , there exists a negative short-term autocorrelation and the $\mathrm{P}_{c}$ may fluctuates excessively. Thus, the $\mathrm{P}_{c}$ should be reverted to the long-term mean values. If $V R(1)$ is more than 1 , the positive short-term autocorrelation signifies that the $\mathrm{P}_{c}$ does not vary significantly. In the mean-averting phase, the values will deviate from the mean so that the critical values should be adjusted based on slope and intercept of the fitting curve. The curve is assumed as the following expression (Lewis, C. D. 1982):

$$
y(x)=a x+b
$$

where $a$ and $b$ denotes the slope and intercept of the fitting curve respectively. The adjusted critical values $\operatorname{REWCV}\left(x_{t}\right)$ can be formulated as:

$$
\operatorname{REWCV}\left(x_{t}\right)= \begin{cases}\bar{x} \cdot\left(2-e^{-a}\right), & a>0 \\ \bar{x}, & a=0 \\ \bar{x} \cdot\left(1+e^{a}\right), & a<0\end{cases}
$$

where $\bar{x}$ is the mean of $x_{t}$, the Euler constant $e$ is approximated as 2.718 .

This adjustment is to reduce the variation range of slope from $(-\infty,+\infty)$ to $[0.5,2]$, so that the mean may be preferably adjusted. In fact, the slope of the fitting curve is within $[-1,1]$, thus the adjusted range of the critical value of the risk lies in $[0.68,1.63]$.

\section{Case study}

Based on investigation and analysis of historical data of Three Gorges Reservoir during year from 2003 to 2007, six indexes are selected as the key environmental factors (Table 2), their maximum and minimum values in SDS system are determined as follow (Table 1):

\begin{tabular}{ccccccc}
\multicolumn{7}{c}{ Table 1 Six selected environmental factors and thresholds } \\
\hline \multirow{2}{*}{ Index } & Visibility & Wind velocity & Water velocity & Channel width & Ship density & Traffic \\
& $(\mathrm{m})$ & $\begin{array}{c}\text { (Beaufort scale) } \\
(\mathrm{m} / \mathrm{s})\end{array}$ & $(\mathrm{m})$ & volume \\
\hline Maximum & $\leqslant 50$ & $>6$ & $>2.5$ & $\leqslant 100$ & $>30$ & $>80(1)$ \\
Minimum & $>1000$ & $\leqslant 1$ & $\leqslant 0.5$ & $>800$ & $\leqslant 5$ & $\leqslant 10(0)$ \\
\hline
\end{tabular}

Subsequently, the grading and equivalent process can be performed by Eq. (7) and Eq. (8). After the 
frequencies of all levels are determined, the probability of causation $P_{C}$ for each environmental factor can be calculated by applying Eq. (2), the corresponding six indexes results are shown in Tables 3 to Table 8 . Note ship density is the number of ships in the upper and lower reaches within a 1000m range around the ship, and traffic volume refers to the number of ships per hour going through a ship traffic flow statistics region near the accident locations. Type of ship is not taken into account because of insufficient accident samples.

Table 2 Key environmental factors from historical accident data (2003-2007)

\begin{tabular}{|c|c|c|c|c|c|c|}
\hline No & $\begin{array}{l}\text { Visibility } \\
\text { (m) }\end{array}$ & $\begin{array}{l}\text { Wind velocity } \\
\text { (Beaufort scale) }\end{array}$ & $\begin{array}{l}\text { Water velocity } \\
\qquad(\mathrm{m} / \mathrm{s})\end{array}$ & $\begin{array}{c}\text { Channel width } \\
\text { (m) }\end{array}$ & Ship density & $\begin{array}{l}\text { Traffic } \\
\text { volume }\end{array}$ \\
\hline 1 & $(0,50]$ & 1 & 1.5 & 800 & 16 & 24 \\
\hline 2 & $(50,100]$ & 1 & 0.5 & 600 & 14 & 10 \\
\hline 3 & $(500,1000]$ & 2 & 0.5 & 400 & 7 & 6 \\
\hline 4 & $(500,1000]$ & 3 & 3 & 300 & 8 & 7 \\
\hline 5 & $(200,300]$ & 1 & 0.5 & 600 & 23 & 50 \\
\hline 6 & $(500,1000]$ & 4 & 0.8 & 400 & 7 & 11 \\
\hline 7 & $>1000$ & 3 & 0.8 & 450 & 8 & 10 \\
\hline 8 & $(50,100]$ & 1 & 0.4 & 700 & 21 & 42 \\
\hline 9 & $>1000$ & 4 & 0.6 & 150 & 7 & 14 \\
\hline 10 & $(200,300]$ & 3 & 1 & 400 & 13 & 28 \\
\hline 11 & $(100,200]$ & 1 & 2.5 & 150 & 4 & 8 \\
\hline 12 & $>1000$ & 6 & 1.2 & 800 & 28 & 56 \\
\hline 13 & $(500,1000]$ & 3 & 0.6 & 600 & 15 & 32 \\
\hline 14 & $(100,200]$ & 1 & 0.8 & 600 & 5 & 16 \\
\hline 15 & $>1000$ & 4 & 0.8 & 750 & 14 & 34 \\
\hline 16 & $>1000$ & 5 & 1 & 550 & 13 & 38 \\
\hline 17 & $(300,500]$ & 3 & 2 & 600 & 31 & 64 \\
\hline 18 & $(300,500]$ & 2 & 0.4 & 400 & 12 & 31 \\
\hline 19 & $(100,200]$ & 2 & 2.2 & 300 & 4 & 10 \\
\hline
\end{tabular}

In fact, no accident should occur as for the current number of accident samples in the extreme environment, including navigational environmental factors. Rational assumptions is also given in the case of no accident samples. If the probability of geometric $P_{G}$ is taken into account, the collision risk would be predicted more rigorously to form a complete logic with both macro-causal and micro-geometric risk. Moreover, division of specific ships may also be taken into account by ship factors in our collision risk model.

Table 3 Evaluation of visibility

\begin{tabular}{ccccc}
\hline Visibility $(\mathrm{m})$ & Number of accidents & Frequency & $\boldsymbol{P}_{\boldsymbol{C}}$ & SDS index \\
\hline$(-\infty, 50]$ & 1 & 0.02 & $2.74 \mathrm{E}-02$ & 1 \\
$(50,100]$ & 2 & 0.03 & $3.65 \mathrm{E}-02$ & 0.8 \\
$(100,200]$ & 3 & 0.08 & $2.05 \mathrm{E}-02$ & 0.7 \\
$(200,300]$ & 2 & 0.1 & $1.10 \mathrm{E}-02$ & 0.6 \\
$(300,500]$ & 2 & 0.12 & $9.13 \mathrm{E}-03$ & 0.4 \\
$(500,1000]$ & 4 & 0.3 & $7.31 \mathrm{E}-03$ & 0.2 \\
$(1000,+\infty)$ & 5 & 0.35 & $7.83 \mathrm{E}-03$ & 0 \\
\hline
\end{tabular}

Table 4 Evaluation of wind velocity 


\begin{tabular}{|c|c|c|c|c|}
\hline Beaufort scale & Number of accidents & Frequency & $P_{C}$ & SDS index \\
\hline$>6$ & 0 & 0.03 & $0.00 E+00$ & 1 \\
\hline 6 & 1 & 0.04 & 1.37E-02 & 0.8 \\
\hline 5 & 1 & 0.08 & $6.85 \mathrm{E}-03$ & 0.7 \\
\hline 4 & 3 & 0.15 & $1.10 \mathrm{E}-02$ & 0.6 \\
\hline 3 & 5 & 0.18 & $1.52 \mathrm{E}-02$ & 0.4 \\
\hline 2 & 3 & 0.2 & $8.22 \mathrm{E}-03$ & 0.2 \\
\hline$\leq 1$ & 6 & 0.3 & $1.10 \mathrm{E}-02$ & 0 \\
\hline \multicolumn{5}{|c|}{ Table 5 Evaluation of water velocity } \\
\hline $\begin{array}{l}\text { Water velocity } \\
\qquad(\mathrm{m} / \mathrm{s})\end{array}$ & Number of accidents & Frequency & $P_{C}$ & SDS index \\
\hline$(2.5,+\infty)$ & 1 & 0.03 & $1.83 \mathrm{E}-02$ & 1 \\
\hline$(2,2.5]$ & 2 & 0.05 & 2.19E-02 & 0.8 \\
\hline$(1.5,2]$ & 1 & 0.08 & $6.85 \mathrm{E}-03$ & 0.7 \\
\hline$(1,1.5]$ & 2 & 0.12 & $9.13 \mathrm{E}-03$ & 0.6 \\
\hline$(0.8,1]$ & 2 & 0.18 & $6.09 \mathrm{E}-03$ & 0.4 \\
\hline$(0.5,0.8]$ & 6 & 0.26 & $1.26 \mathrm{E}-02$ & 0.2 \\
\hline$(-\infty, 0.5]$ & 5 & 0.28 & $9.78 \mathrm{E}-03$ & 0 \\
\hline \multicolumn{5}{|c|}{ Table 6 Evaluation of channel width } \\
\hline Channel width $(\mathrm{m})$ & Number of accidents & Frequency & $\boldsymbol{P}_{C}$ & SDS index \\
\hline$(-\infty, 100]$ & 0 & 0.05 & $0.00 \mathrm{E}+00$ & 1 \\
\hline$(100,200]$ & 2 & 0.05 & 2.19E-02 & 0.8 \\
\hline$(200,400]$ & 6 & 0.15 & 2.19E-02 & 0.7 \\
\hline$(400,500]$ & 1 & 0.25 & $2.19 \mathrm{E}-03$ & 0.6 \\
\hline$(500,600]$ & 6 & 0.2 & $1.64 \mathrm{E}-02$ & 0.4 \\
\hline$(600,800]$ & 4 & 0.2 & $1.10 \mathrm{E}-02$ & 0.2 \\
\hline$(800,+\infty)$ & 0 & 0.1 & $0.00 \mathrm{E}+00$ & 0 \\
\hline \multicolumn{5}{|c|}{ Table 7 Evaluation of ship density } \\
\hline Ship density & Number of accidents & Frequency & $P_{C}$ & SDS index \\
\hline$(30,+\infty)$ & 1 & 0.04 & $1.37 \mathrm{E}-02$ & 1 \\
\hline$(25,30]$ & 1 & 0.05 & $1.10 \mathrm{E}-02$ & 0.8 \\
\hline$(20,25]$ & 2 & 0.08 & $1.37 \mathrm{E}-02$ & 0.7 \\
\hline$(15,20]$ & 1 & 0.28 & $1.96 \mathrm{E}-03$ & 0.6 \\
\hline$(10,15]$ & 6 & 0.25 & $1.32 \mathrm{E}-02$ & 0.4 \\
\hline$(5,10]$ & 5 & 0.2 & 1.37E-02 & 0.2 \\
\hline$(-\infty, 5]$ & 3 & 0.1 & $1.64 \mathrm{E}-02$ & 0 \\
\hline \multicolumn{5}{|c|}{ Table 8 Evaluation of traffic volume } \\
\hline Traffic volume & Number of accidents & Frequency & $P_{C}$ & SDS index \\
\hline$(60,+\infty)$ & 1 & 0.04 & $1.37 \mathrm{E}-02$ & 1 \\
\hline$(50,60]$ & 1 & 0.08 & $6.85 \mathrm{E}-03$ & 0.8 \\
\hline$(40,50]$ & 2 & 0.15 & 7.31E-03 & 0.7 \\
\hline$(30,40]$ & 4 & 0.2 & $1.10 \mathrm{E}-02$ & 0.6 \\
\hline$(20,30]$ & 2 & 0.2 & $5.48 \mathrm{E}-03$ & 0.4 \\
\hline$(10,20]$ & 3 & 0.18 & $9.13 \mathrm{E}-03$ & 0.2 \\
\hline
\end{tabular}




\begin{tabular}{|c|c|c|c|c|c|c|}
\hline \multirow[b]{3}{*}{ No } & \multicolumn{2}{|l|}{$(-\infty, 10]$} & 6 & \multirow{2}{*}{\multicolumn{2}{|c|}{ riance ratio test }} & \multirow[t]{2}{*}{0} \\
\hline & & & ble 8 Results o & & & \\
\hline & $P_{C}$ & $\begin{array}{c}\text { Mean of } \\
\boldsymbol{x}_{\boldsymbol{t}} \\
\end{array}$ & $\begin{array}{c}\text { Variance of } \\
\boldsymbol{x}_{\boldsymbol{t}} \\
\end{array}$ & $\log \left(p_{t} / p_{t-k}\right)$ & $\begin{array}{c}\text { Variance of } \\
\log \left(p_{t} / p_{t-k}\right)\end{array}$ & $V R(1)$ \\
\hline 1 & $6.59 \mathrm{E}-02$ & & & - & & \\
\hline 2 & 1.09E-01 & & & $2.18 \mathrm{E}-01$ & & \\
\hline 3 & $8.28 \mathrm{E}-02$ & & & $-1.18 \mathrm{E}-01$ & & \\
\hline 4 & $9.83 \mathrm{E}-02$ & & & $7.44 \mathrm{E}-02$ & & \\
\hline 5 & $6.91 \mathrm{E}-02$ & & & $-1.53 \mathrm{E}-01$ & & \\
\hline 6 & 7.57E-02 & & & $3.91 \mathrm{E}-02$ & & \\
\hline 7 & 7.35E-02 & & & $-1.26 \mathrm{E}-02$ & & \\
\hline 8 & 7.89E-02 & & & $3.07 E-02$ & & \\
\hline 9 & $7.62 \mathrm{E}-02$ & & & $-1.52 \mathrm{E}-02$ & & \\
\hline 10 & $7.28 \mathrm{E}-02$ & $8.01 \mathrm{E}-02$ & 2.67E-04 & $-1.96 \mathrm{E}-02$ & $1.62 \mathrm{E}-02$ & $6.04 \mathrm{E}+01$ \\
\hline 11 & 1.14E-01 & & & $1.94 \mathrm{E}-01$ & & \\
\hline 12 & $5.94 \mathrm{E}-02$ & & & $-2.82 \mathrm{E}-01$ & & \\
\hline 13 & 7.57E-02 & & & $1.05 \mathrm{E}-01$ & & \\
\hline 14 & $8.62 \mathrm{E}-02$ & & & $5.61 \mathrm{E}-02$ & & \\
\hline 15 & $6.65 \mathrm{E}-02$ & & & $-1.12 \mathrm{E}-01$ & & \\
\hline 16 & $6.13 \mathrm{E}-02$ & & & $-3.53 \mathrm{E}-02$ & & \\
\hline 17 & 7.35E-02 & & & $7.88 \mathrm{E}-02$ & & \\
\hline 18 & 7.32E-02 & & & $-2.09 \mathrm{E}-03$ & & \\
\hline 19 & $1.11 \mathrm{E}-01$ & & & $1.81 \mathrm{E}-01$ & & \\
\hline
\end{tabular}

The discrete points are fitted in Fig. 3 to Fig. 8 by plotting the SDS grade on X-axis and the $P_{C}$ values on Yaxis. These curves clearly reveal the relationships between different levels of environmental factors and the $P_{C}$ values. For example, the visibility curve shows that the $P_{C}$ grows along with the growth of SDS $(<0.8)$ and the value also increases sharply when SDS exceeds 0.6. More attentions should be taken by operators when the SDS of visibility is more than 0.6 (its corresponding actual visibility is less than $300 \mathrm{~m}$ ). The fall of values (SDS >0.8) may be caused by the error of few samples. If the number of previous accidents corresponding to a visibility $(<50 \mathrm{~m})$ increases, the causation probability is expected to rise continuously along with the growth of SDS (Fig. 3).

The wind velocity curve (Fig. 4) shows that the $P_{C}$ does not change consistently with SDS. However, it is found that no previous accidents can be corresponded to a wind velocity level $(\geq 6)$. If the wind velocity level ( $\geq 6$ ) is assumed as the occurrence threshold for a ship collision, $P_{C}$ increases with the growth of SDS, but the curve fluctuates by a small margin. When the SDS is greater than 0.72 and the wind velocity level is above 5 , the probability of a collision increases remarkably so that more attention should be paid in these cases.

The fitted curve for water velocity is similar to a combination of those for visibility and wind velocity. The $P_{C}$ values increases along with growth of SDS $(<0.8)$, but smaller fluctuations are observed. It is found that the value increases rapidly when SDS exceeds 0.68 , which corresponds to the situation when water velocity is greater than $1.8 \mathrm{~m} / \mathrm{s}$. Similarly, the falling part of the curve with growth of SDS (>0.8) may attribute to only several samples. If the number of accidents corresponding to water velocity $(>2.5 \mathrm{~m} / \mathrm{s})$ rises, the $P_{C}$ increases along with growth of SDS without limit (Fig. 5).

Without historical collision accident data of channel width less than $100 \mathrm{~m}$ or greater than $800 \mathrm{~m}$ would result in a peak value when SDS is within $[0.4,0.75]$. However, though these channel width had been taken into account, the $P_{C}$ would not change considerably (Fig. 6). For instance, the $P_{C}$ (SDS=0.6) is lower than the value when $\mathrm{SDS}=0.4$, and the values (SDS>0.6) would see a peak when $S D S=0.75$. A possible reason is that the channel width has little effect when SDS $<0.4$ corresponding to a channel width $(>600 \mathrm{~m})$. Thus, effects of the channel width are attenuated quickly. Conversely, a channel width $(<200 \mathrm{~m})$ corresponding to SDS $(>0.75)$ significantly influences the 
value so that the human factors may become more significant, thus a downward trend of the values is observed.

The fitted curve of the ship density only shows that $P_{C}$ changes significantly when SDS=0.6 and the values keep at very low level. This fact suggests that the $P_{C}$ is independent of change except when SDS is close to 0.6 (the corresponding ship density: 15-20). If the number of accidents corresponding to the ship density $(<5$ or $>30)$ rises, a higher ship density leads to an increase in $P_{C}$ values (Fig. 7).

Irrespective of any change of the ship traffic volume, the $P_{C}$ is always increasing. In Fig.8, the value is minimum when SDS=0.4 which corresponds to a ship traffic volume ranges from 20 to 30 . Moreover, higher ship traffic volumes lead to larger $P_{C}$ values with the growth of accidents related to ship traffic volumes (>60; Fig. 8). It can be concluded that the $P_{C}$ values may fall when an appropriate ship traffic volume is maintained. However, the value also increases when the ship traffic volume is lower than a threshold value. Thus, operators should pay more attentions in such situation.

All environmental factors can be visualized in a same coordinate plane (see Fig. 9). In the context of the human-ship-environment system theory, accident occurs due to interaction of various factors. Here only the view of navigation environment is analyzed so that there exists some congenital deficiencies. Currently, environmental factors tend to deteriorate and the risk of accidents should also be deteriorated in theory. Whereas, there will be "explicit" or "implicit" risk changes due to the fact that human and environmental factors are not fully considered. Human factors will hinder deterioration of accident risks in case the risk of accidents is perceived. Thus, when the harsh conditions are more significant, human factors will always avoid this deterioration (a kind of human instinct). Thus, the depiction of the curves may conform to our actual cognition where the effects of risk trends of a humanvessel-environment system should be reflected only in the context of studying the navigational environmental factors.

The $P_{C}$ values of visibility are greater than any other factors when SDS (>0.7). Thus, it should be highly focused for collision accident early warning. Moreover, the peak values should also be noticed in Fig.6 (SDS>0.65) and Fig.5 (SDS>0.75). Notably, the value remains high even when SDS of ship traffic volume is 0 . The $P_{C}$ values of every factor are combined by applying Eq. (3) so that the accidents may be distributed chronologically. The reversion to the mean is verified based from Eq. (11) to Eq. (14) and the results are listed in Table 8. Because $V R(1)>1$, the accidents are in the mean-averting phase. Thus the mean is adjusted by Eq. (15) and is shown in Table 9.

\begin{tabular}{ccccc}
\multicolumn{4}{c}{ Table 9 Adjusted results and REWCV } \\
\hline$P_{C}$ fitting curve & slope & $\left(1+e^{a}\right) / 2$ & mean of $x_{t}$ & $R E W C V\left(x_{t}\right)$ \\
\hline$y=-0.0002 x+0.0825$ & $-2.00 \mathrm{E}-04$ & 0.9999 & $8.01 \mathrm{E}-02$ & $8.01 \mathrm{E}-02$ \\
\hline
\end{tabular}

The above results mean that a collision accident occurs and the probability of accident is high when $P_{C}$ is no less than 0.08012 . This value can be used as to issue an early warnings. Note the REWCV does not represent the complete $P_{C}$ value for an accident but show there would be a higher probability of accident than usual if such environmental factors are involved, in spite of any human or ship factors.

\section{Verification of results}

Constraints are set by rules such as the Navigation Standards for Inland Waterways and Maritime Safety Administration in China. Based on a comparison of these standards presented in Table 10, it can be concluded that 
the derived results are essentially consistent with those for visibility, wind velocity, and water velocity in Chinese rules, confirming the practical applicability of this study. The collision accident data of 2008 is collected to verify the applicability of the early-warning critical value for inland waterway. The key environmental factors and the calculated $P_{C}$ values are given in Table 11.

\begin{tabular}{|c|c|c|c|}
\hline $\begin{array}{l}\text { Environmental } \\
\text { factors }\end{array}$ & Chinese standard & Conclusion of this study & Remark \\
\hline Visibility & $\begin{array}{l}\text { From ship to upper } \\
\text { reaches: }<500 \mathrm{~m} \\
\text { From ship to lower } \\
\text { reaches: }<1000 \mathrm{~m}\end{array}$ & $\begin{array}{l}\text { Probability increases sharply while visibility } \\
\qquad(<300 \mathrm{~m})\end{array}$ & $\begin{array}{c}\text { Chinese standard is } \\
\text { more stringent }\end{array}$ \\
\hline Wind velocity & Level 6 and higher & $\begin{array}{l}\text { Probability increases sharply while the wind } \\
\text { velocity level }(>5)\end{array}$ & Almost similar \\
\hline Water velocity & $>2.0 \mathrm{~m} / \mathrm{s}$ & $\begin{array}{l}\text { Probability increases sharply while the water } \\
\text { velocity }(>1.8 \mathrm{~m} / \mathrm{s}) .\end{array}$ & $\begin{array}{l}\text { Chinese standard is } \\
\text { less stringent }\end{array}$ \\
\hline Channel width & Not Applicable & $\begin{array}{l}P_{C} \text { peaks while the channel width ranges } \\
\text { from } 200 \mathrm{~m} \text { to } 500 \mathrm{~m} \text {. }\end{array}$ & Not Applicable \\
\hline Ship density & Not Applicable & $\begin{array}{c}P_{C} \text { remains almost constant and its } \\
\text { minimum value is among } 15-20 \text {. }\end{array}$ & Not Applicable \\
\hline Traffic volume & Not Applicable & $\begin{array}{c}\text { Irrespective of any change of the ship traffic } \\
\text { volume, the } P_{C} \text { increases but its minimum } \\
\text { value is among } 20-30 .\end{array}$ & Not Applicable \\
\hline $\begin{array}{c}\boldsymbol{P}_{\boldsymbol{C}} \text { of environmental } \\
\text { factors }\end{array}$ & Not Applicable & $\geq 8.01 E-02$ & Not Applicable \\
\hline
\end{tabular}

Table 11 Key environmental factors of collision accidents in 2008 and the calculated $P_{C}$ values

\begin{tabular}{cccccccc}
\hline \multicolumn{2}{c}{ Table 11 Key environmental factors of collision accidents in 2008 and the calculated $P_{C}$ values } \\
\hline No & $\begin{array}{c}\text { Visibility } \\
(\mathrm{m})\end{array}$ & $\begin{array}{c}\text { Wind } \\
\text { (Beaufort scale) }\end{array}$ & $\begin{array}{c}\text { Water velocity } \\
(\mathrm{m} / \mathrm{s})\end{array}$ & $\begin{array}{c}\text { Channel } \\
\text { width }(\mathrm{m})\end{array}$ & $\begin{array}{c}\text { Ship } \\
\text { density }\end{array}$ & \multicolumn{2}{c}{ Traffic } \\
\hline 1 & $(500,1000]$ & 6 & 1.2 & 300 & 27 & 31 & $1.18 \mathrm{E}-01$ \\
2 & $(300,500]$ & 2 & 1.1 & 240 & 12 & 16 & $8.99 \mathrm{E}-02$ \\
3 & $(100,200]$ & $\leq 1$ & 2.2 & 370 & 21 & 27 & $1.22 \mathrm{E}-01$ \\
4 & $(100,200]$ & $\leq 1$ & 0.9 & 420 & 26 & 32 & $9.31 \mathrm{E}-02$ \\
5 & $>1000$ & 3 & 1.2 & 620 & 31 & 27 & $8.55 \mathrm{E}-02$ \\
\hline
\end{tabular}

The mean $P_{C}$ value in 2008 is 0.101632 , which is much larger than the critical value (0.08012) calculated from year 2003 to 2007 . This indicates that the $P_{C}$ value are increasing in 2008 . The minimum value for 20032008 (0.061329) is similar to that for 2003-2007 (0.059426), which indicates that the minimum value could be used for the risk warning. Note it would be detrimental to use the minimum value for accident early warning when its greater likelihood had been taken into account. Thus, an appropriate warning value between the minimum and maximum $P_{C}$ may be determined based on calculation of collisions from 2003 to 2010 . The longer study period may change the values. Comparison results (Table 12) indicate that the values related to a same environmental factor vary with the number of accidents in every statistical period. Environmental factors vary significantly and all $P_{C}$ increase substantially in the study of year 2008 and 2009.

Table 12 Comparison results of $P_{C}$ values

\begin{tabular}{|c|c|c|c|c|c|}
\hline Year & No. & $\boldsymbol{P}_{\boldsymbol{C}}(2003-2007)$ & $\boldsymbol{P}_{\boldsymbol{C}}(2003-2008)$ & $\boldsymbol{P}_{\boldsymbol{C}}(2003-2009)$ & $\boldsymbol{P}_{\boldsymbol{C}}(2003-2010)$ \\
\hline 2003-2007 & 1 & 6.59E-02 & $7.62 \mathrm{E}-02$ & $1.23 \mathrm{E}-01$ & $1.12 \mathrm{E}-01$ \\
\hline
\end{tabular}




\begin{tabular}{|c|c|c|c|c|c|}
\hline & & & & & \\
\hline & 2 & $1.09 \mathrm{E}-01$ & $9.55 \mathrm{E}-02$ & $1.23 \mathrm{E}-01$ & $1.11 \mathrm{E}-01$ \\
\hline & 3 & $8.28 \mathrm{E}-02$ & $8.20 \mathrm{E}-02$ & $1.06 \mathrm{E}-01$ & $9.53 \mathrm{E}-02$ \\
\hline & 4 & $9.83 \mathrm{E}-02$ & $9.51 \mathrm{E}-02$ & $1.31 \mathrm{E}-01$ & $1.15 \mathrm{E}-01$ \\
\hline & 5 & $6.91 \mathrm{E}-02$ & $6.64 \mathrm{E}-02$ & $9.55 \mathrm{E}-02$ & 8.76E-02 \\
\hline & 6 & 7.57E-02 & 7.62E-02 & $1.18 \mathrm{E}-01$ & $1.06 \mathrm{E}-01$ \\
\hline & 7 & $7.35 \mathrm{E}-02$ & 6.69E-02 & $9.09 \mathrm{E}-02$ & $8.28 \mathrm{E}-02$ \\
\hline & 8 & $7.89 \mathrm{E}-02$ & $8.54 \mathrm{E}-02$ & $1.22 \mathrm{E}-01$ & $1.11 \mathrm{E}-01$ \\
\hline & 9 & $7.62 \mathrm{E}-02$ & $6.73 \mathrm{E}-02$ & $9.63 \mathrm{E}-02$ & 8.94E-02 \\
\hline & 10 & $7.28 \mathrm{E}-02$ & $8.13 \mathrm{E}-02$ & $1.23 \mathrm{E}-01$ & $1.08 \mathrm{E}-01$ \\
\hline & 11 & $1.14 \mathrm{E}-01$ & $1.18 \mathrm{E}-01$ & $1.33 \mathrm{E}-01$ & $1.21 \mathrm{E}-01$ \\
\hline & 12 & $5.94 \mathrm{E}-02$ & $9.42 \mathrm{E}-02$ & $1.04 \mathrm{E}-01$ & $9.45 \mathrm{E}-02$ \\
\hline & 13 & 7.57E-02 & $7.36 \mathrm{E}-02$ & $8.61 \mathrm{E}-02$ & 8.01E-02 \\
\hline & 14 & $8.62 \mathrm{E}-02$ & $8.88 \mathrm{E}-02$ & $1.08 \mathrm{E}-01$ & $1.04 \mathrm{E}-01$ \\
\hline & 15 & $6.65 \mathrm{E}-02$ & $6.54 \mathrm{E}-02$ & 7.70E-02 & 7.41E-02 \\
\hline & 16 & $6.13 \mathrm{E}-02$ & $6.13 \mathrm{E}-02$ & $7.08 \mathrm{E}-02$ & $6.73 \mathrm{E}-02$ \\
\hline & 17 & $7.35 \mathrm{E}-02$ & 8.03E-02 & $1.05 \mathrm{E}-01$ & $9.39 \mathrm{E}-02$ \\
\hline & 18 & $7.32 \mathrm{E}-02$ & $8.26 \mathrm{E}-02$ & $1.04 \mathrm{E}-01$ & $9.54 \mathrm{E}-02$ \\
\hline & 19 & $1.11 \mathrm{E}-01$ & $1.24 \mathrm{E}-01$ & $1.50 \mathrm{E}-01$ & $1.36 \mathrm{E}-01$ \\
\hline \multirow{5}{*}{2008} & 1 & & $1.18 \mathrm{E}-01$ & $1.33 \mathrm{E}-01$ & $1.18 \mathrm{E}-01$ \\
\hline & 2 & & 8.99E-02 & $1.30 \mathrm{E}-01$ & 1.17E-01 \\
\hline & 3 & & $1.22 \mathrm{E}-01$ & $1.71 \mathrm{E}-01$ & $1.51 \mathrm{E}-01$ \\
\hline & 4 & & $9.31 \mathrm{E}-02$ & $1.02 \mathrm{E}-01$ & $9.22 \mathrm{E}-02$ \\
\hline & 5 & & 8.55E-02 & $1.18 \mathrm{E}-01$ & $1.06 \mathrm{E}-01$ \\
\hline \multirow{15}{*}{2009} & 1 & & & $1.70 \mathrm{E}-01$ & $1.52 \mathrm{E}-01$ \\
\hline & 2 & & & $9.93 \mathrm{E}-02$ & $9.14 \mathrm{E}-02$ \\
\hline & 3 & & & $1.12 \mathrm{E}-01$ & $1.02 \mathrm{E}-01$ \\
\hline & 4 & & & $1.63 \mathrm{E}-01$ & $1.47 \mathrm{E}-01$ \\
\hline & 5 & & & $1.31 \mathrm{E}-01$ & 1.17E-01 \\
\hline & 6 & & & $1.34 \mathrm{E}-01$ & $1.19 \mathrm{E}-01$ \\
\hline & 7 & & & $1.30 \mathrm{E}-01$ & $1.18 \mathrm{E}-01$ \\
\hline & 8 & & & $9.97 \mathrm{E}-02$ & $9.19 \mathrm{E}-02$ \\
\hline & 9 & & & $1.53 \mathrm{E}-01$ & $1.37 \mathrm{E}-01$ \\
\hline & 10 & & & $1.28 \mathrm{E}-01$ & $1.13 \mathrm{E}-01$ \\
\hline & 11 & & & $1.41 \mathrm{E}-01$ & $1.28 \mathrm{E}-01$ \\
\hline & 12 & & & 1.09E-01 & $9.82 \mathrm{E}-02$ \\
\hline & 13 & & & 1.34E-01 & $1.21 \mathrm{E}-01$ \\
\hline & 14 & & & $9.05 \mathrm{E}-02$ & 8.53E-02 \\
\hline & 15 & & & $1.00 \mathrm{E}-01$ & $9.05 \mathrm{E}-02$ \\
\hline \multirow{2}{*}{2010} & 1 & & & & 8.94E-02 \\
\hline & 2 & & & & 7.46E-02 \\
\hline Mean & & 8.01E-02 & 0.08706 & 8.71E-02 & $1.06 \mathrm{E}-01$ \\
\hline
\end{tabular}

The mean $P_{C}$ values of environmental factors are minimal in 2003-2007, and the value tends to increase in 2003-2008, a slowly increase is also observed in 2003-2009. Besides, the value seems to keep at a constant from 2003 to 2010 . Thus, the $P_{C}$ is larger for the same environmental factors from 2003 to 2008 and the accidents are more likely to occur. The high values in 2009 may be caused by three times of average accidents number. The decrease of the mean value in 2010 is due to the number of accidents falling below the average in that year. The numbers of accidents in 2003-2008 (Fig. 10) indicates that the choice of statistical period greatly affects the values 
of a certain factor (Fig. 11); for example, the number of accidents in 2009 changes significantly.

Based on a further analysis of changes on $P_{C}$ values, all accident samples (2003-2010) were sorted chronologically. Then, the first 20 samples were used for calculation of $P_{C}$ and then it was determined to replace the prior three samples with the following three ones. This method is based on the time between the first and last samples and ensures that the number of accidents should be the same during each calculation period. The results are shown in Fig. 12.

Fig. 12 shows a clear growth trend of $P_{C}$ values for the fourth collision accident in 2008 (Line (2)), and the values for the fifth collision accident in 2009 (Line (4)) is more stable. The $P_{C}$ trends indicate a rapid increase of the values for the eighth collision accident in 2009 (Line (5)). The values for the fourteenth accident in 2009 (Line (7) shows that a decreasing trend becomes less tremendous than that in 2010. Understanding the upward trends in values between Lines (2) and (6) could result in the effective control. Based on our results, it is suggested that the following issues should be necessarily concerned.

A. REWCV should be accurately determined to enable early warnings: the mean value of $P_{C}$ of environmental factors was regarded as the risk-warning critical value and the slope of the linear fit was taken as the adjustment parameter here. The slope changes slightly so that the adjustment range should be correspondingly small. Because the number of accidents varies substantially each year, the linear fit also varies greatly. The calculated fit for one year cannot be applied to calculate the critical value in the following year. A comparison of critical value for each statistical period is shown in Tables 13 and 14. If $e^{-a}$ or $e^{a}$ in Eq. (15) is replaced by $\mathrm{e}^{-100 \mathrm{a}}\left(\mathrm{e}^{100 \mathrm{a}}\right)$ and the slope is more than 0.001 , the corrected value would be close to the mean for the next calculation process. Thus, the critical value can be calculated based on the following equation, where $\mu$ can be adjusted according to the calculation.

$$
\operatorname{REWCV}\left(x_{t}\right)= \begin{cases}\bar{x} \cdot\left(2-e^{-\mu a}\right), & a>0 \\ \bar{x}, & a=0 \\ \bar{x} \cdot\left(1+e^{\mu a}\right) / 2, & a<0\end{cases}
$$

Table 13 Comparison results of risk early-warning critical value

\begin{tabular}{cccccc}
\hline Year & $2003-2007$ & $2003-2008$ & $2003-2009$ & $2003-2010$ & Index \\
\hline REWCV & $7.97 \mathrm{E}-02$ & $8.71 \mathrm{E}-02$ & $1.18 \mathrm{E}-01$ & $1.06 \mathrm{E}-01$ & \\
Mean & $8.01 \mathrm{E}-02$ & $8.71 \mathrm{E}-02$ & $1.18 \mathrm{E}-01$ & $1.06 \mathrm{E}-01$ & $\mu=1$ \\
Slope of fitting line & $-2.00 \mathrm{E}-04$ & $9.00 \mathrm{E}-04$ & $5.00 \mathrm{E}-04$ & $2.00 \mathrm{E}-04$ & \\
Intercept of fitting line & $8.25 \mathrm{E}-02$ & $7.55 \mathrm{E}-02$ & $1.09 \mathrm{E}-01$ & $1.02 \mathrm{E}-01$ & \\
\hline
\end{tabular}

Table 14 Comparison results of risk early-warning critical value (REWCV*)

\begin{tabular}{ccccccccccc}
\hline No. & (1) & (2) & (3) & (4) & (5) & (6) & (7) & (8) & Index \\
\hline REWCV & $7.69 \mathrm{E}-02$ & $9.38 \mathrm{E}-02$ & $1.15 \mathrm{E}-01$ & $1.47 \mathrm{E}-01$ & $1.86 \mathrm{E}-01$ & $2.33 \mathrm{E}-01$ & $2.79 \mathrm{E}-01$ & $2.29 \mathrm{E}-01$ & $\mu=1$ \\
REWCV* & $7.84 \mathrm{E}-02$ & $1.11 \mathrm{E}-01$ & $1.31 \mathrm{E}-01$ & $1.60 \mathrm{E}-01$ & $2.39 \mathrm{E}-01$ & $2.74 \mathrm{E}-01$ & $2.50 \mathrm{E}-01$ & $1.81 \mathrm{E}-01$ & $\mu=100$ \\
Mean & $7.69 \mathrm{E}-02$ & $9.36 \mathrm{E}-02$ & $1.15 \mathrm{E}-01$ & $1.46 \mathrm{E}-01$ & $1.86 \mathrm{E}-01$ & $2.32 \mathrm{E}-01$ & $2.79 \mathrm{E}-01$ & $2.30 \mathrm{E}-01$ & & \\
Slope of fitting line & $2.00 \mathrm{E}-04$ & $2.00 \mathrm{E}-03$ & $1.50 \mathrm{E}-03$ & $1.00 \mathrm{E}-03$ & $3.40 \mathrm{E}-03$ & $2.00 \mathrm{E}-03$ & $-2.40 \mathrm{E}-03$ & $-5.60 \mathrm{E}-03$ & \\
\hline
\end{tabular}




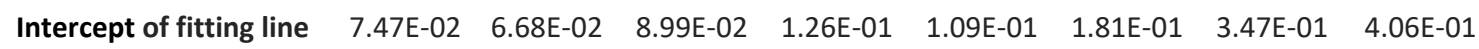

\section{B. The precise relationship between the change of $P_{C}$ and the number of collision accident should be}

determined: it can be concluded that if the $P_{C}$ values related to environmental factors increase, the mean value of $P_{C}$ will increase so as to result in a greater risk. Moreover, if the increased risk is not recognized and processed, the number of accident would rise accordingly. On the other hand, if the increased risk might be recognized, appropriate countermeasures would be taken according to human and ship factors so that the number of accidents may decrease. In contrast, if the $P_{C}$ values related to environmental factors decrease, a lower risk for the same environmental factors and an increase in the number of accident would be observed. In addition, if operators underestimate the risk of environmental factors, a negative response would occur and the number of accidents would increase similarly.

As for broad acceptance of our method and results, shipping operations are directly forbidden in those cases (such as wind strength $>$ Grade 6; the flood rate $>2.5 \mathrm{~m} / \mathrm{s}$ during the flood period and visibility $<500 \mathrm{~m}$ (in heavy fog) based on data collected by Yangtze River Maritime Affair Bureau of China Maritime Safety Administration (China MSA) in several extreme cases in its navigation restrictions. After the Eastern Star Tragedy, more specified administration provisions were issued to present more detailed regulations on navigation environment restrictions for sailing ships and those ready for sailing. Our primary concern is that the risk of those accidents that may be perceived straightforwardly in any extreme navigation environment is called as the explicit risk. Unfortunately, more navigation environment factors are acceptable (namely those extreme conditions stipulated by the authority are not be transcended) as for specific types of accidents, but the probability of the risk of accidents is high (for example: foggy visibility $>800 \mathrm{~m}$ or the flood rate $>2.0 \mathrm{~m} / \mathrm{s}$ ). Whether the interaction of many environmental factors may give rise to effects of extreme navigational factors should be studied by means of a large number of accident samples. This is defined as the implicit risk which has been actually determined in this study and may be identified to some extent. Thus, it is believed that a better promotion significance should be provided after continuous development and improvement.

\section{Conclusions}

Studying the probability of causation $P_{C}$ of collision accident is a highly complicated task which is akin to using a "black box" in many cases where one knows the input and output parameters rather than the actual process (namely, how to obtain outputs remains unknown). Even if there were a perfect model or method, it would be difficult to determine the basic $P_{C} \mathrm{P}$ corresponding to each environmental factor. Our early warning method was put forward here based on the effects of various environmental factors on ship navigation and assumptions of the facts that the future probability of accident can be determined if these environmental factors of previous accident may be reconstructed and the hidden risks can be recognized if changes of the REWCV (risk early-warning critical value) may be determined. In such case, the accident risk can be perceived in advance and the corresponding number of accident can be reduced accordingly. Moreover, the REWCV for previous accident can be used to issue early warnings. In comparison of the Bayesian network analysis (Trucco, 2008) and the popular fault tree methods (Antao, 2006), our method is more intuitive though the REWCV is only an estimate of the actual accident probability. In addition, our early warning method and calculations are relatively simple so that early warnings can be issued to prevent future collisions by continuously updating the historical accident data. This 
method can be proved of great applicable value.

\section{Acknowledgements}

This work is supported by the Key Project in the National Science \& Technology Pillar Program (Grant No. 2015BAG20B05), the National Natural Science Foundation of China (Grant No. 51379170) and the Fundamental Research Funds for the Central Universities (Grant No.2016-HY-B1-11).

\section{References}

1. Antao, P., Soares, C. G., 2006. Fault-tree models of accident scenarios of RoPax vessels. Int J Autom Comput 3 (2), 107-116.

2. Balmat, J.F., Lafont, F., Maifret, R., et al. 2009. MAritime RISk Assessment (MARISA), a fuzzy approach to define an individual ship risk factor. Ocean Eng 36 (15), 1278-1286.

3. Chen, C.H., Khoo, L.P., Chong, Y.T., et al. 2014. Knowledge discovery using genetic algorithm for maritime situational awareness. Expert Syst Appl 41 (6), 2742-2753.

4. Darbra, R.M., Casal, J. 2004. Historical analysis of accidents in seaports. Saf Sci 42 (2), 85-98.

5. Fan, X., Zhang, Q., Zhou, F., Tan, Z., Wang, M., 2013. Model of ship domain in river water, J Dalian Marit Univ 39 (1), $46-48$.

6. Goerlandt, F., Kujala, P. 2011. Traffic simulation based ship collision probability modeling. Reliab Eng Syst Saf 96 (1), $91-107$.

7. Guest, P.G, 2012. Numerical Methods of Curve Fitting. Cambridge University Press, UK.

8. Hanninen, M., Kujala, P. 2009. The effect of causation probability on the ship collision analysis. Accidents probabilities in selected areas of the Gulf of Finland. In: Weintrit A, editor. Marine Navigation and Safety of Sea Transportation. Taylor \& Francis, London, UK, pp. 267-272.

9. Hara, K., Nakamura, S. 1995. A comprehensive assessment system for the maritime traffic environment. Saf Sci 19 (2-3), 203215.

10. Hetherington, C., Flin, R., Mearns, K. 2006. Safety in shipping: The human element. J Saf Res 37 (4), 401-411.

11. Kaneko, F. 2002. Methods for probabilistic safety assessments of ships. J Mar Sci Technol 7 (1), 1-16

12. Lewis, C.D. 1982. Industrial and Business Forecasting Methods: A Practical Guide to Exponential Smoothing and Curve Fitting. Butterworth-Heinemann, Location.

13. Li, S., Meng, Q., Qu, X. 2012. An overview of maritime waterway quantitative risk assessment models. Risk Anal 32 (3), $496-512$.

14. Macduff, T., 1974. Probability of vessel collisions. Ocean Ind 9 (9), 144-148.

15. Montewka, J., Hinz, T., Kujala, P., Matusiak, J. 2010. Probability modelling of vessel collisions. Reliab Eng Syst Safe 95 (5), $573-$ 589.

16. Papanikolaou, A., Bitha, K., Eliopoulou, E., et al. 2014. Statistical analysis of ship accidents that occurred in the period $1990-2012$ and assessment of safety level of ship types. In: Proceedings of the Maritime Technology and Engineering Conference (MARTECH), location, pp. 227-233.

17. Statheros, T., Howells, G., Maier, K.M.D. 2008. Autonomous ship collision avoidance navigation concepts, technologies and techniques. J Navigation 61 (01), 129-142.

18. Suyi Li, et al.; An Overview of Maritime Waterway Quantitative Risk Assessment Models, Risk Analysis, Vol. 32, No.3, 2012.

19. Toffoli, A., Lefevre, J.M., Bitner-Gregersen, E., et al. 2005. Towards the identification of warning criteria: analysis of a ship accident database. Appl Ocean Res 27 (6), 281-291.

20. Toffoli, A., Lefevre, J.M., Monbaliu, J., Savina, H., Bitner-Grgersen, E. 2003. Freak waves: clues for prediction in ship accidents? In: Proceedings of the 13th International Offshore and Polar Engineering Conference, Hawaii, USA, pp. 23-29.

21. Trucco, P., Cagno, E., Ruggeri, F., et al. 2008. A Bayesian belief network modelling of organisational factors in risk analysis: A case study in maritime transportation. Reliab Eng Syst Safe 93(6), 845-856. 
22. Wright, J.H. 2000. Alternative variance-ratio tests using ranks and signs. J Bus Econ Stat 18 (1), 1-9.

23. Xu, D.L., Yang, J.B., Wang, Y.M. 2006. The evidential reasoning approach for multi-attribute decision analysis under interval uncertainty. Eur J Oper Res 174 (3), 1914-1943.

24. Xu, Z., Mu, J., Ji, Y., 2004. A study of 3D model of ship domain for inland waterway. J Wuhan Univ Technol (Transp Sci Eng) 28 (3), 380-383. 